\title{
A EXPERIÊNCIA DE FORMAÇÃO DE EDUCADORES MUNICIPAIS EM EA, NA ARTICULAÇÃO DE TRÊS MUNICÍPIOS DA BAIXADA FLUMINENSE-RJ
}

\author{
Ana Maria Marques Santos \\ Universidade Federal Rural do Rio de Janeiro (UFRRJ) \\ Cristiane Cardoso \\ Universidade Federal Rural do Rio de Janeiro (UFRRJ)
}

\begin{abstract}
A EXPERIÊNCIA DE FORMAÇÃO DE EDUCADORES MUNICIPAIS EM EA, NAARTICULAÇÃO DE TRÊS MUNICÍPIOS DA BAIXADA FLUMINENS-RJ

Resumo: Este texto aborda a experiência de formação de educadores municipais em EA, desenvovilda mediante a articulação entre três municípios da Baixada Fluminense/RJ (Itaguaí, Nova Iguaçu e Mesquita) e o Campus Nova Iguaçu da Universidade Federal Rural do Rio de Janeiro (UFRRJ). Possui como foco a indissociabilidade entre ensino-pesquisaextensão, tomadas como urgentes e indissociáveis, assumindo as práxis socioambientais como Educação Ambiental Crítica e partindo da produção de trabalhos e saberes desenvolvida na prática da pesquisa-ensino-extensão do Grupo de Estudos e Pesquisa em Educação Ambiental, Diversidade e Sustentabilidade (GEPEADS/UFRRJ).Argumenta que o desenvolvimento do trabalho pode apontar para a perspectiva da formação de um potencial grupo de educadores ambientais, que dinamizem, desvelem, problematizem e possam, de fato, intervir, via processo educativo, em suas realidades socioambientais locais, guardadas as proporções dos enfrentamentos e a minimização dos problemas ambientais daquelas áreas mais específicas e a que pertencem os sujeitos implicados e impactados.

Palavras-chave: Formação de Educadores Ambientais, EA Crítica, indissociabilildade de pesquisa-ensino-extensão.
\end{abstract}

THE FORMATION EXPERIENCE OF EDUCATORS IN MUNICIPAL AND IN JOINT BAIXADA MUNICIPALITIES OF THREE FLUMINENSE-RJ

Abstract: This paper seeks to address the training experience of local educators $E A$, the articulation of three municipalities of Baixada Fluminense-RJ - (Itaguai, Nova Iguaçu and Mesquita) and the Campus Nova Iguaçu-RJ of the UFRRJ. Has as focus the indivisibility of teaching-research-extension, taken here as urgent and inseparable, taking social and environmental practice as a Critical Environmental Education, starting production work and knowledge developed in the practice of teaching-research-extension of the Task Force and Research in Environmental Education, Diversity and Sustainability, GEPEADS, UFRRJ. The development work can point to the prospect of the formation of a potential group of environmental educators that streamline, unveil, problematize and can actually intervene, via educational process in their local social and environmental realities, kept the proportions of the fighting and minimizing environmental problems of those more specific areas and that belong to those involved and impacted.

Key words: Training of Environmental Educators, EA Review, indissociability research, education, extension. 


\section{INTRODUÇÃO}

Este artigo é objeto do exercício permanente GrupodeEstudosePesquisaemEducaçãoAmbiental, Diversidade e Sustentabilidade (GEPEADS), Universidade Federal Rural do Rio de Janeiro (UFRRJ), em assumir práxis socioambientais como uma Educação Ambiental Crítica (EAC), partindo da produção de trabalhos e saberes desenvolvidos na prática da pesquisa-ensino-extensão do grupo, e aqui, explicitamente, assumimos a representação neste trabalho, desenvolvido por esse coletivo, nesse projeto indissociável do tripé ora explicitado ${ }^{1}$.

Acreditamos indispensável à Educação Ambiental em sua vertente Crítica, o enfrentamento do atual contexto de acirramento da problemática socioambiental em sentido lato, em especial, no que tange o avanço do capital e suas graves consequências socioambientais. Nesse sentido, a perspectiva da pesquisa-ensino-extensão de forma ampla, e especificamente a que diz respeito à EAC, são tomadas aqui como urgentes e indissocioáveis. A EAC, aqui pensada e defendida, se propõe a compreender e agir sobre: as especificidades dos grupos sociais em seus embates; a forma como produzem seus meios de vida na interação com o modo de produção da sociedade capitalista; e o modo como criam suas condutas e se situam na sociedade para que se estabeleçam processos coletivos pautados no diálogo e na problematização do mundo e da nação, vinculando à educação a construção da cidadania.

Propomos apresentar neste artigo, uma das experiências realizadas alicerçadas neste preâmbulo, realizada pelo GEPEADS/UFRRJ e, para que numa troca de saberes, busquemos delimitar e almejar possibilidades desta estratégia na formação de educadores ambientais.

Organizamos desta forma a articulação e constituição deste artigo, buscando abordar a experiência de formação de educadores municipais em EA, na articulação de três municípios da Baixada Fluminense-RJ (Itaguai, Nova Iguaçu e Mesquita) e destes, com a Universidade, através do Campus Nova Iguaçu-RJ, via grupo de pesquisa GEPEADS.

Desta forma, esta primeira fala, via expresso neste artigo, visa abordar os resultados obtidos da experiência de formação de educadores municipais em EA, na articulação de três municípios da Baixada Fluminense-RJ (Itaguai, Nova Iguaçu e Mesquita). Trabalho que foi realizado ao longo de 2012 e 2013 pelo GEPEADS.

\section{O PROJETO}

No ano de 2011 iniciamos uma assessoria metodológica para a construção participativa da Política Municipal de Educação Ambiental no Município de Mesquita - RJ, considerando as políticas
Nacional e Estadual de Educação Ambiental, bem como o Programa Nacional de Educação Ambiental (ProNEA); a identificação e mapeamento de ações de Educação Ambiental do Município, visando a construção do Programa Municipal de Educação Ambiental (ProMEA) (RIO DE JANEIRO, 2009).

O desenvolvimento deste projeto através de suas etapas e atividades buscou integrar: as atividades de pesquisa-ação participativa, investigação-ação participante e outras metodologias e técnicas que destacassem o protagonismo da comunidade envolvida; as estratégias para a geração e socialização de conhecimentos da EAC; a mobilização comunitária; e o desenvolvimento de um projeto que teve como foco a geração de política e programa destinados ao Município no âmbito da EAC, sustentável e democrática. Esta assessoria gerou uma série de resultados e ações que nos permitiu um amadurecimento enquanto grupo e novas ações educativas pela Baixada Fluminense.

Assim, como fruto deste trabalho, resolvemos dar continuidade as nossas ações ampliando a nossa área de atuação a outros municípios. Com o objetivo de fomentar a formação em Educação Ambiental Critica de cunho participativo e com intervenção socioambiental, enviamos sob o título Educação Ambiental na formação de Educadores da Baixada Fluminense/RJ o projeto para Fundação Carlos Chagas Filho de Amparo à Pesquisa do Estado do Rio de Janeiro (FAPERJ), baseados em edital que apoia ações relacionadas o cunho da extensão e pesquisa no Estado do Rio de Janeiro. Tendo sido nosso projeto aprovado e com recursos a ele destinados, subsidiamos suas ações. O projeto iniciou-se em 2012, em sua concepção, e em fevereiro de 2013, em sua execução, até novembro de 2013. Entretanto, ações organizativas, de desdobramentos e produção relativas ao projeto permanecem até o presente momento.

Os trabalhos foram organizados em encontros presenciais e atividades à distância, inclusive acompanhamento/apoio aos educadorescursistas pelos alunos-bolsistas em atividades relacionadas ao curso em seus locais de trabalho. A carga horária total do curso foi de $80 \mathrm{~h} / \mathrm{a}$ para os que almejaram desenvolver projeto pedagógico e 40h/a para os que não o desenvolveram, distribuídas em 3 etapas, cada uma com duração de 6 meses, ou seja, os educadores-cursistas que apresentaram trabalho final cursaram $80 \mathrm{~h} / \mathrm{a}$ e obtiveram essa carga horária, e os que não realizaram esta última atividade tiveram certificação de apenas 40h/a.

As inscrições foram realizadas através de ficha própria do projeto, através das Secretarias de Educação municipais envolvidas (Municípios de Nova Iguaçu, Itaguaí e Mesquita) e das IES envolvidas. Cada turma teve 50 vagas destinadas a educadores-cursistas e alunos de graduação de universidade. Ficaram distribuídas, ao final das 
inscrições, duas turmas: uma que comportou o município de Itaguaí e outra que comportou os municípios de Nova Iguaçu, Mesquita e Universidade, respeitadas as demandas das inscrições. Foram também, realizadas visitas às escolas de Itaguaí, Nova Iguaçu, Mesquita e associações de moradores do entorno do Parque para divulgação do curso de formação de educadores ambientais.

A concepção teórico-metodológica de trabalho envolveu aulas expositivas e participativas, debates com as turmas, apresentação e discussão de vídeos, dinâmicas de grupo integrando os participantes do processo de formação, bem como aula de campo a fim de resgatar a importância do contexto social e histórico local, apresentação e discussão da proposta de pesquisa a ser construída e desenvolvida coletivamente sobre a realidade socioambiental local. Sob a responsabilidade dos educadores-cursistas houve a produção de textos e relatórios (avaliação da aula de campo, atividades do curso, elaboração de roteiro de trabalho final), trabalhos de grupo, apresentação de trabalho final sobre a forma de apresentações em power point dos projetos realizados a fim de expor os trabalhos desenvolvidos e de proporcionar maior interação entre os cursistas e seus projetos.

Em relação às atividades à distância (para professores eeducadores-cursistas)foram realizadas orientações para as atividades propostas e para a elaboração dos projetos pedagógicos de extensão, que foram praticados e com suas considerações e trâmite entregues pelos participantes no Seminário final do curso, fazendo jus estes, da certificação de $80 \mathrm{~h}$.

Inicialmente foi estruturada uma turma de 50 educadores-cursistas no Município de Itaguaí, que envolveu dois alunos de graduação, em especial dos cursos de Geografia e Pedagogia, do Campus de Seropédica da UFRRJ no apoio e acompanhamento das atividades, juntamente com a equipe pedagógica composta por professores da própria instituição e colaboradores. E, simultaneamente, foi composta uma outra turma com o mesmo número de vagas no Município de Nova Iguaçu, que abarcou os professores da rede municipal e os agentes atuantes do Parque Municipal de Nova Iguaçu. Esta fase contou com o apoio de dois graduandos do Instituto Multidisciplinar da UFRRJ. Dessa forma, o curso foi realizado nos dois Municípios, simultaneamente, em dias alternados.

As etapas previstas, que correspondiam cada uma, a 6 (seis) meses de trabalho, contados a partir da liberação da verba da FAPERJ (ocorrida em novembro de 2012), foram plenamente cumpridas, a saber: $1^{\text {a }}$ Etapa: Correspondente aos 6 primeiros meses - Mobilização de implantação do Projeto - setembro de 2012 a fevereiro de 2013, com: Reuniões de planejamento de logística pela equipe coordenadora; Ações de divulgação do Projeto;
Elaboração e viabilização do curso de extensão e Arregimentação e inscrição dos participantes - fevereiro 2013; $2^{\mathbf{a}}$ Etapa, correspondente aos 6 meses consecutivos trataram de conformar os Encontros formativos de pesquisa e extensão, com a realização dos 8 (oito) encontros presenciais e acompanhamentos in loco e virtuais, a partir de março de 2013 a novembro de 2013; 3 ${ }^{\mathrm{a}}$ Etapa, que correspondeu aos 6 (seis) meses finais, guardou as produções dos resultados de pesquisa e extensão, em um movimento de orientação e acompanhamento do planejamento e execução dos projetos de extensão realizados pelos educadorescursistas. Culminou com a apresentação dos trabalhos desenvolvidos nessa etapa em Seminário de encerramento do curso. Atividade esta, integrada com todos os educadores-cursistas.

Em um Seminário de culminância do curso, foram apresentados pelos partícipes-cursistas, todos os projetos desenvolvidos na terceira parte da ação integrada ao curso, com o encontro dos três municípios envolvidos, no Teatro Municipal de Itaguaí - RJ, em atividade de dia inteiro, com almoço de integração.

O objetivo foi o de elucidar o planejamento previsto na construção, desenvolvimento e ação dos projetos realizados junto à comunidade escolar e não-escolar, realizados pelos cursistas ao longo de todo o período do curso. Também nesse sentido, o Seminário de encerramento, contou com a configuração participativa de cada sujeito envolvido na formação: docentes, cursistas, comunidade na qual o projeto se deu - escolas, parques, universidade, unidades administrativas.

Essa dinâmica, contou ainda com a participação inicial da parceria com a Universidade Federal do Ceará (UFCE), na presença do Professor Dr. João Batista de Figueiredo, que deu inicio aos trabalhos, dialogando entre a Educação Ambiental e as vertentes populares de sua interlocução.

\section{A EXPERIÊNCIA DE FORMAÇÃO DE EDUCADORES MUNICIPAIS EM EA}

A formação de educadores ambientais numa sociedade marcada por grave crise permanece a nosso ver, sendo um dos grandes desafios diante dos problemas socioambientais postos, particularmente na Baixada Fluminense - $\mathrm{RJ}^{2}$, lócus de realização deste projeto. Contudo a atuação desses educadores se torna mais difícil ainda, uma vez que, na maioria das vezes, os processos formativos da sociedade direcionam os educadores a um caminho único, predeterminado pela lógica hegemônica. Dessa forma, o educador em sua atuação, corre o risco de corroborar para a manutenção do status quo ao multiplicar conhecimentos, informações e práticas conservadoras de Educação Ambiental. Ou, opostamente, caminhar no sentido contra 
hegemônico, contribuindo na transformação da realidade por meio de uma postura crítica de enfrentamento dos problemas socioambientais. Esse foi o direcionamento tomado na concepção e execução deste projeto.

Para tanto, permaneceu em foco a formação de educadores ambientais, direcionados por uma vertente crítica e emancipatória, que buscou instrumentalizar esses educadores a atuarem em seus espaços formais e não formais de educação, considerados espaços e sujeitos se localizam em uma sociedade comprovadamente, injusta e desigual, tanto no que se refere aos fatores econômicos, quanto aos problemas e danos ambientais desigualmente distribuídos pela sociedade.

Consideramos, então, a EAC como constituinte de uma educação mais ampla, uma vez que pretende formar sujeitos sociais em seus processos de luta por melhores condições de vida que está intrínseca a uma melhor qualidade ambiental. Este sujeito explicita, participa e atua sobre as contradições dos problemas socioambientais, estabelece uma prática pedagógica contextualizada no espaço-tempo numa perspectiva inclusiva das diferentes esferas da sociedade e em um processo de desalienação política pelo exercício da cidadania.

A EAC, aqui pensada e defendida, se propõe fundamentalmente a compreender: as especificidades dos grupos sociais em seus embates; a forma como produzem seus meios de vida na interação com o modo de produção da sociedade capitalista; e o modo como criam suas condutas e se situam na sociedade para que se estabeleçam processos coletivos pautados no diálogo e na problematização do mundo e da nação, vinculando à educação a construção da cidadania.

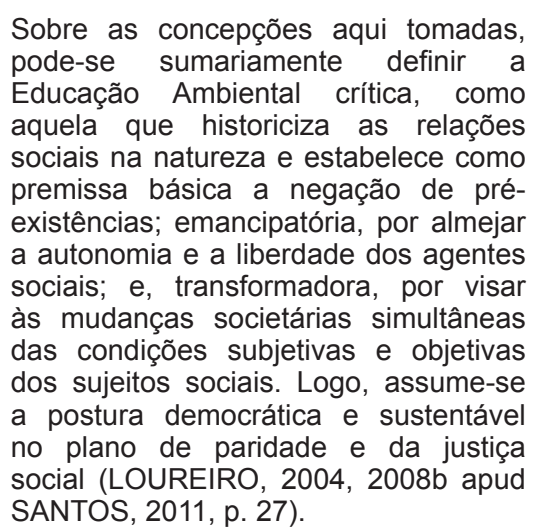

Desta forma, torna-se estratégico para o embate hegemônico que alimente um mundo melhor, o contínuo desenvolvimento de iniciativas que envolvam projetos de cunho socioambiental. Uma destas estratégias foi a realização deste projeto de pesquisa e extensão que buscou abarcar a formação continuada a fim de que os educadores pudessem se sentir mais seguros em relação às diversas demandas que emergem a cada dia.

Nesta direção, Imbernón (2010) afirma que, a formação é legítima quando contribui para o desenvolvimento profissional no âmbito do trabalho e de melhoria das aprendizagens profissionais. Com um olhar mais atento para a formação do educador, fator imprescindível para a promoção de uma realidade de maior eficácia da educação brasileira, foi publicada pelo Ministério da Educação a Portaria 1.328 de 23 de setembro de 2011, que institui a Rede Nacional de Formação Continuada do Magistério da Educação Básica Pública (BRASIL, 2011). Esta legislação pretende ir ao encontro do compromisso social da Universidade, que deve ser muito mais efetivo e fazer opções por ações que visem a transformar profundamente a sociedade, na busca da conquista dos direitos sociais, civis e políticos dos indivíduos e das comunidades. Buscamos pensar o projeto, também nesse sentido.

Entendemos ser imprescindível na Universidade o princípio articulador do ensino, da pesquisa e da extensão para todos os cursos de formação do educador. Segundo Macedo (2008, p. 116), a preocupação com esse tripé vem sendo apontada por vários estudiosos que defendem

[...] a universidade como o lócus privilegiado para a formação do educador ao compreenderem que ela é a única em condições de estabelecer essa relação.

Deste compromisso firma-se o sentido de práxis pedagógica, como conceito fundante das ações formativas do GEPEADS, em que o educador em sua atuação reafirme sua prática de pensar, de criar, de refazer a leitura do mundo que o cerca para transformá-lo, e do papel da educação. O permanente diálogo da Universidade com a sociedade favorece que a práxis pedagógica - que une dialeticamente reflexão-ação, teoria-prática - se manifeste no cotidiano desses educadores, assim como na academia.

Dessa forma, é necessário refletir e (re) afirmar a atuação da Universidade considerando projetos de extensão-pesquisa-ensino que estejam a serviço da sociedade e a criação e o estímulo de parcerias em todos os níveis de ensino. A formação de educadores - instrumento de transformação social - tem um papel primordial no processo de desenvolvimento humano, uma vez que prepara a geração de hoje para formar a geração de amanhã.

A Universidade precisa alargar fronteiras, ver-se além no tempo e no espaço, ver o país e o mundo à frente, especialmente no que diz respeito às questões socioambientais. Assim, a Universidade precisa pensar global e agir local, pois é, por meio da valorização das questões socio-político-educacionais que a sociedade terá 
acesso ao desenvolvimento, à unidade/diversidade sociocultural e, só assim, conseguiremos manter vivos os saberes, as experiências e a difusão da cultura comprometida com as transformações para a sustentabilidade socioambiental.

Este projeto nasceu justamente do trabalho que desenvolvemos sobre a construção da política (2010) e do programa de Educação Ambiental (2010) no município de Mesquita, também na Baixada Fluminense $^{3}$. Uma das grandes demandas dos municípios é a formação de educadores ambientais críticos. A nossa prioridade, em seu curso, foi a formação de 100 educadores, distribuídos entre os municípios de Itaguaí, Nova Iguaçu e Mesquita.

\begin{abstract}
A formação emancipatória se apresenta como característica marcante, sendo solicitada para a qualificação dos debates nas construções e proposições de políticas públicas no município (nos municípios). A participação popular necessita avançar nesse sentido, pois é potencial para as intervenções que dêem continuidade aos caminhos já percorridos e que, de fato apóiem e agreguem força aos processos decisórios daquela comunidade, ampliando suas concepções de realidade-mundo e dos saberes ali existentes e isso implica diretamente na relação professor-escola-comunidad e. (SANTOS, 2011, p. 2, grifo nosso).
\end{abstract}

Com isso, e pautados em conhecimentos, reflexões, e propostas metodológicas desenvolvidas no/pelo GEPEADS/UFRRJ, objetivou-se com esse projeto a ampliação das oportunidades de intervenção social, inserindo a Educação Ambiental em processos formativos. Através da oferta de curso de extensão fundamentado e fundamentando pesquisas que buscaram desenvolver conceitos, práticas e vivências participativas de Educação Ambiental, em busca de justiça socioambiental, viabilizado e possível, via caminhos delineados pelos nossos objetivos mais específicos, podemos afirmar o alcance dos objetivos deste projeto.

\section{PARA NÃO CONCLUIR}

O desenvolvimento do trabalho pode apontar para a perspectiva da formação de um potencial grupo de educadores ambientais, que dinamizem, desvelem, problematizem e possam de fato intervir, via processo educativo, em suas realidades socioambientais locais, guardadas as proporções dos enfrentamentos e a minimização dos problemas ambientais daquelas áreas mais específicas e a que pertencem os sujeitos implicados e impactados. A metodologia de formação de dinamizadores, proporcionou, mais objetivamente, agentes envolvidos, que almejaramse com a ampliada repercussão pelo efeito indireto instrumentalizador, seja via escola, universidade, movimentos sociais, e demais instituições que o exercício do curso proposto possa ter atingido ou vir a atingir naquelas determinadas regiões e onde seus agentes alcancem com o ato educativo.

De certa maneira, podemos afirmar que esse intento foi atingido, uma vez que que a metodologia de trabalho produziu não só eventos mais espaços de diálogo, produção e interlocução de ações participativas, com produções concretas em ações nas escolas (projetos de produção), apresentação teórico-metodológica em eventos locais, regionais, nacionais e internacionais (SANTOS et al., 2013; PLÁCIDO et al., 2013) visando discutir, difundir e avaliar o trabalho desenvolvido, o diálogo com comunidades tradicionais (pescadores, ribeirinhos, agricultores familiares, escolas do campo).

O fim do projeto não é o fim de nossas ações. Consideramos que este projeto é o início das atividades que poderão gerar muitos frutos no futuro. É um grande desafio formar educadores aptos para atuar em uma sociedade onde os excluídos são a maioria da população e a injustiça socioambiental impera, na Baixada Fluminense, esta realidade esta ainda mais presente. Reverter esse quadro não é uma tarefa simples, uma vez que envolve muitos atores sociais, cada um deles com seus propósitos e ambições e dentro de uma organização social instituída por relações desiguais de poder. Assim, é imprescindível a consolidação de uma educação crítica em espaços de formação dos educadores, valorizando a diversidade de saberes, promovendo conhecimentos e práticas sustentáveis, ao invés de se limitarem a ações rígidas e ao reprodutivismo neste contexto de complexidade e conflitos socioambientais. Entendemos que uma educação comprometida com as questões socioambientais é aquela que promove a cidadania e a emancipação do indivíduo em ações coletivas e engajadas no enfrentamento das desigualdades baseadas em relações de dominação e exploração, causadoras de degradação social e ambiental. É essa educação ambiental que acreditamos e tentamos refletir com estes projetos desenvolvidos nestes lugares.

\section{REFERÊNCIAS}

BRASIL. Ministério da Educação e Cultura. Portaria 1.328, de 23 de setembro de 2011. Institui a Rede Nacional de Formação Continuada dos Profissionais do Magistério da Educação Básica Pública. Brasília, DF, 2011.

IMBERNÓN, F. Formação docente e profissional: formar-se para a mudança e a incerteza. 8. ed. São Paulo: Cortez, 2010.

INSTITUTO NACIONAL DE ESTUDOS E PESQUISAS EDUCACIONAIS ANÍSIO TEIXEIRA. 
Índice de Desenvolvimento da Educação Básica. Brasília, DF, 2015. Disponível em<http://www.inep. gov.br>. Acesso em: 1 jul. 2012.

MACEDO, J. M. A formação do pedagogo em tempos neoliberais: a experiência da UESB. Vitória da Conquista: Edições UESB, 2008.

PLÁCIDO, P. et al. A educação ambiental crítica na formação de educadores da Baixada Fluminense/RJ, Brasil. In: BARRIOS, D.; MARRERO, N.; IGLESIAS, G. Memorias del $1^{\text {a }}$ Congreso de Extensión de la Asociación de Universidades Grupo Montevideo - AUGM - Extenso 2013. Montevideo: Ed. Universidad de la República, 2013.

SANTOS, A. M. M. Um caso de participação popular na construção de uma política pública: a PMEA e o ProMEA Mesquita/RJ. In: JORNADA INTERNACIONAL DE POLÍTICAS PÚBLICAS, 5., 2011, São Luís. Anais... São Luis: PPGPP/UFMA, 2011.

et al. Educação ambiental crítica e políticas públicas: experiências de uma práxis socioambiental. In: JORNADA INTERNACIONAL DE POLÍTICAS PÚBLICAS, 6., 2013, São Luís. Anais... São Luis: PPGPP/UFMA, 2013.

RIO DE JANEIRO. Câmara Municipal de Mesquita. Lei $n^{\circ} 601$, de 29 de dezembro de 2009. Política Municipal de Educação Ambiental do Município de Mesquita. Mesquita, 2009.

\section{NOTAS}

1 Este é um dos artigos que compôs a mesa temática coordenada: Em caminho, tecendo a indissociabilidade da pesquisa, ensino e extensão em educação ambiental: experiências de práxis socioambientais como transformação social, apresentada na VII Jornada Internacional de Políticas Públicas (JOINPP) Para além da crise Global: experiências e antecipações concretas, realizada na UFMA, de 25 a 28 de agosto de 2015. São Luiz do Maranhão, MA, Brasil.

2 Destacamos dessa realidade o que tange ao número de professores com e sem formação na graduação. Mais especificamente que, na Baixada Fluminense há uma enorme demanda por formação inicial, antes mesmo da continuada. Avançando para os municípios da Baixada Fluminense - interesse de estudo e compreensão dessa realidade, uma vez que nela diretamente inseridos junto com a UFRRJ, Instituto Multidisciplinar de Nova Iguaçu: temos então, as realidades de ausência de formação inicial caracterizadas nesses municípios, considerando as redes municipais e estadual e a rede privada; Mesquita, Belford Roxo, Nilópolis, Duque de Caxias, Japeri, Paracambi, São Joao de Meriti, Nova Iguaçu, Queimados. A exemplo, o município de Mesquita, são cerca de 320 (trezentos e vinte professores), entre as redes municipal e estadual, sem formação inicial de graduação atuando na rede, e ainda 254 (duzentos e cinquenta e quarto) na rede privada. Esses são dados significativos. Tratam-se de professores que estão atuando ainda e tão somente com o ensino médio, com carência de qualificação. Apesar de tratarmos em nosso projeto da formação continuada, esses dados são significativos para só pensarmos os processos formativos da região. Os números de docentes por escolaridade, referência nacional no ano 2012, podem ser encontrados no Instituto Nacional de Estudos e Pesquisas Educacionais Anísio Teixeira (INEP) (2015).

3 De forma mais sistematizada a construção participativa da Política e do Progama Municipal de EA, partiu das ações de pesquisa e extensão realizadas pela Universidade Federal Rural do Rio de Janeiro (UFRRJ), Campus Nova Iguaçu e a Prefeitura Municipal de Mesquita/RJ, por meio das Secretarias Municipais de Meio Ambiente (SEMUAM) e de Educação (SEMED), no decorrer dos anos de 2009 e 2010. Esta iniciativa conjunta se refere a um processo de construção participativa. Além das instituições descritas, o trabalho contou também com o apoio e participação da Universidade Federal do Rio de Janeiro (UFRJ), e do Instituto do Meio Ambiente e dos Recursos Naturais Renováveis (IBAMA-RJ).

\section{Ana Maria Marques Santos}

Graduada e Licenciada em Psicologia

Doutora em Ecologia Social pelo Programa de PósGraduação em Psicossociologia de Comunidades e Ecologia Social (EICOS) da Universidade Federal do Rio de Janeiro (UFRJ)

Professora Adjunta do Departamento de Educação e Sociedade (DES) e do Programa de Pós-Graduação em Geografia (PPGGEO) da Universidade Federal Rural do Rio de Janeiro (UFRRJ)

E-mail: anamarques.ufrrj@gmail.com

\section{Cristiane Cardoso}

Licenciada e Bacharel em Geografia

Doutora em Geografia pela Universidade Federal Fluminense (UFF)

Professora Adjunta do Departamento de Geografia, Professora do Programa de Pós-graduação em Geografia (PPGGeo) e do Programa de Pós-graduação em Práticas em Desenvolvimento Sustentável da Universidade Federal Rural do Rio de Janeiro (UFRRJ)

E-mail: cristianecardoso1977@yahoo.com.br

Universidade Federal Rural do Rio de Janeiro - UFRRJ BR-465, Km 7 Seropédica, Rio de Janeiro/RJ CEP. 23.897-000 